\title{
Factors affecting healthcare utilization for low back pain among nurses in Gondar town, northwest Ethiopia, 2018: a cross-sectional study
}

\author{
Tesfaye Hambisa Mekonnen ${ }^{*}$ and Dawit Getachew Yenealem
}

\begin{abstract}
Objective: The objective of this study was to investigate level and factors affecting healthcare utilization for low back pain (LBP) among nurses in Gondar town, Ethiopia. A healthcare-based cross-sectional study was conducted from March to April 2018. We included 422 nurses using stratified sampling technique. A binary logistic regression analysis was performed using SPSS version 20 to identify factors associated with healthcare utilization.

Results: A total of 422 nurses with 100\% response rate participated in this study. The majority, $54.8 \%(\mathrm{~N}=277)$ were females. Mean age was 21.54 (SD \pm 4.99$)$ years. Of the 64\% ( $N=270)$ LBP sufferers, $25.4 \%(N=107)[95 \% \mathrm{Cl}(21.1,29.6)]$ had used healthcare services at least once in the previous 12 months. Sex [AOR: 1.82; $95 \% \mathrm{Cl}(1.03,3.43)]$, educational level [AOR: 1.13; $95 \% \mathrm{Cl}(1.01,3.40]$, perceived disability [AOR: $2.11 ; 95 \% \mathrm{Cl}(1.66,3.20)]$, and perceived severity [AOR: $2.06 ; 95 \% \mathrm{Cl}(1.27,3.51)]$ were associated factors. This study reveals that healthcare service utilization for low back pain was not common practices among nurses. Strategies that focus on nurses' gender and educational level differences should be in place to promote care usage for low back pains.
\end{abstract}

Keywords: Low back pain, Nurses, Healthcare utilization, Ethiopia

\section{Introduction}

The health and economic burdens of occupational-related low back pain (LBP) are often superseding. It has been shown that LBP causes an estimated 21.7 million disability adjusted life years (DALYs) accounting for about one-third of all occupational disabilities [1]. The burden of LBP also entails a profound negative impact on the quality of life, productivity, and work performance [2-4]. Globally, there has been a plethora of research conducted on the prevalence and risk factors arousing LBP among healthcare workers, particularly nurses [5-10].

Despite the ample studies available on the prevalence and risk factors of LBP, information is scant on the practices of seeking healthcare services for the ailments

*Correspondence: tajan2022@gmail.com

Department of Environmental and Occupational Health and Safety, Institute of Public Health, College of Medicine and Health Sciences, University of Gondar, P.O.Box 196, Gondar, Ethiopia among nurse professionals [11]. It has been showed that experiencing back pain for more than 6 weeks is a serious health problem owing to certain kinds of treatment services [12, 13]. Depending on the conditions, numerous treatment options are available for LBP. Self-care, such as taking the necessary rests, ice or heat, massage, pain relievers, and gentle stretches are usually eminent treatment strategies [12]. The use of drugs, like non-steroidal anti-inflammatory drugs, muscle relaxant, analgesics, and steroidal treatment [4] and physical/exercise therapy, such as ultrasound, diathermy, yoga, chiropractic manipulation, and acupuncture have been showed to be beneficial to treat chronic or recurrent low back pain disorders $[3,12,14-17]$.

Despite the treatment options available, care seeking for LBP among nurses is often peculiar. For instance, a study done in the Netherlands indicated that the majority of LBP sufferers had not sought treatment [18]. Literature illustrates that variations in the level of treatment 
utilization for LBP ranges from 4.54 to $28 \%[19,20]$. Another report demonstrated that only $16 \%$ of medical care was sought for low back pain [21]. Moreover, various investigations have exhibited that there are a number of notable factors, including sex, perceived disability [20, 22, 23], duration of back pain [19], and perceived severity [23] which can affect health service utilization for back pain conditions. It has also been shown that the decisions to seek care for LBP is related to economic and occupational risk factors [19] and the nature of pain [7, 24].

To date, in Ethiopia, evidence is meager on the status and a number of factors affecting healthcare utilization due to LBP among nurse professionals. The current study is, therefore, aimed to determine the status and identify factors affecting healthcare utilization due to back pain among nurses in Gondar town, northwest Ethiopia.

\section{Main text \\ Methods \\ Study design, setting and period}

A healthcare-based cross-sectional study was conducted from March to April 2018. Healthcare facilities in Gondar town were the study setting. The town is located $748 \mathrm{~km}$ to the northwest of Addis Ababa, the capital of Ethiopia. In the town, there are two hospitals (public and private), employing more than 600 nurse professionals, five public health centers, and more than ten private clinics, employing more than 391 nurse healthcare workers. We included the two hospitals purposively and 8 randomly selected health centers (five from private and 3 from public) to attain the required sample.

\section{Populations and sample size}

Nurses who had worked for at least 12 months prior to the study period were included and we excluded those on sick, annual, maternity and other leaves. A single population proportion formula was employed to calculate the sample size with $\mathrm{n}$, (minimum sample size), $\mathrm{z}=1.96$ (critical value) with $95 \% \mathrm{CI}, \mathrm{p}=50 \%$ (the proportion of healthcare utilization for low back pain), and $d=5 \%$ (margin of error). Hence, $n=\left(\left(z^{2}\right)(p)\left(1 \_p\right)\right) \div d^{2} ; n=(1.96)^{2}(0.5)$ $\left(1 \_0.5\right) \div(0.05)^{2}=384$ and assuming a $10 \%$ no response, the final sample was $=384+38.4=422$. We considered the $50 \%$ proportion of care utilization because there has not been similar previous study accessed on the topic in Ethiopia. Healthcare workers were stratified according to the type of health facility (private \& public).

\section{Data collection tools and techniques}

The data collection was conducted using a structured and interviewer-administered questionnaire. We assessed the prevalence of low back pain by the standardized Nordic Questionnaire [25]. Perceived severity and disability of low back pain were evaluated according to the Von Korff et al. [26]. The 10-items generic job satisfaction scale questionnaire was used to assess the satisfaction of nurses with their jobs [27]. We also assessed job stress using the 8-items job stress scale questionnaire [28].

\section{Data analysis and quality control}

Data collection tool was developed in English and translated to Amharic, the local language, and retranslated to English by language experts. Three well-experienced data collectors and two supervisors involved in the data collection. The data collectors and supervisors had taken training and orientation for 2 days. We also conducted a pre-test at the neighboring Kola Diba hospital on $5 \%$ of the sample. Based on the pretest, we minimized the amount of questions and corrected some other ambiguities.

Data were entered into EPI info version 7.1.5.2 and exported to SPSS version 20 software for analysis. We described the results using frequencies, percentages, means, and standard deviations. The reliability of data collection instrument was tested and we found a reliable Cronbach's Alpha score (Cronbach's Alpha $=0.88$ ). A variable inflation factor (VIF) was employed to check the multicollinearity and found no evidence of collinearity $(\mathrm{VIF}<5)$. A multivariable logistic regression model was used to identify potential confounders. We verified goodness of fit model using the Hosmer and Lemeshow test ( $p$ value $>0.05$ ). The model was also evaluated using the area under the receiver operating characteristics (ROC) curve. Hence, the test showed that $89.1 \%$ of the positive outcome of interest/care utilization/could be correctly predicted by the model $(\mathrm{AUC}=0.891 ; \mathrm{p}=0001)$.

\section{Operational definition}

Perceived severity: A pain intensity score of $\geq 50$ or $<3$ disability points [26].

Perceived disability: A pain disability point score of 3-6 points [26].

Stressed worker: The workplace stress scale score of 21 or above [28].

Job satisfied worker: The generic job satisfaction scale score of 32 or above [27].

\section{Results}

\section{Socio-demographic characteristics}

Response rate was $100 \%$. The majority, $53.8 \%(\mathrm{~N}=227)$ were females. About $72.7 \%(\mathrm{~N}=307)$ were in the age group of 25-35 years. The mean age was 21.54 $(\mathrm{SD} \pm 4.499)$ years. Of the respondents, $77.9 \%(\mathrm{~N}=329)$ were Amhara and 54.3\% $(\mathrm{N}=229)$ were married. The majority of the participants, $55.4 \%(\mathrm{~N}=234)$ were diploma graduates (Table 1). High proportions, $86.3 \%$ 
Table 1 Socio-demographic characteristics of nurses in Gondar town,, Ethiopia, 2018 ( $N=422)$

\begin{tabular}{|c|c|c|}
\hline Variables & Frequency & Percent (\%) \\
\hline \multicolumn{3}{|l|}{ Sex } \\
\hline Male & 195 & 46.2 \\
\hline Female & 227 & 54.8 \\
\hline \multicolumn{3}{|l|}{ Age } \\
\hline$\leq 24$ & 36 & 8.5 \\
\hline $25-35$ & 307 & 72.7 \\
\hline$>35$ & 79 & 18.7 \\
\hline \multicolumn{3}{|l|}{ Religion } \\
\hline Orthodox & 250 & 59.2 \\
\hline Muslim & 118 & 28.0 \\
\hline Protestant & 54 & 12.8 \\
\hline \multicolumn{3}{|l|}{ Marital status } \\
\hline Single & 159 & 37.8 \\
\hline Married & 229 & 54.2 \\
\hline Separated/divorced/widowed & 34 & 8.0 \\
\hline \multicolumn{3}{|l|}{ Educational level } \\
\hline Diploma & 234 & 55.4 \\
\hline First degree (BSc) & 124 & 29.3 \\
\hline Masters degree & 64 & 15.2 \\
\hline \multicolumn{3}{|l|}{ Monthly salary in BIRR } \\
\hline$\leq 3500$ & 148 & 35.1 \\
\hline $3501-4500$ & 73 & 17.3 \\
\hline$>4500$ & 201 & 47.6 \\
\hline
\end{tabular}

$(\mathrm{N}=364)$ of the participants were permanent employees, $51 \%(\mathrm{~N}=219)$ worked more than $8 \mathrm{~h}$ per day, $73.5 \%$ $(\mathrm{N}=310)$ said they worked over time, $58.3 \%(\mathrm{~N}=246)$ worked night shift, $5.7 \%(\mathrm{~N}=24)$ day shift, $31 \%(\mathrm{~N}=131)$ served on both shifts, and $5 \%(\mathrm{~N}=21)$ no shift. Over three-fourth, $76.3 \%(\mathrm{~N}=322)$ and $38.4 \%(\mathrm{~N}=162)$ of the participants reported that there was pre-employment and periodic medical examination services at their work, respectively. A limited proportions, $28.8 \%(\mathrm{~N}=109)$ of the respondents marked that they worked in outpatient departments (OPD) (Fig. 1).

\section{Level of health care utilization due to low back pains}

Out of the reported $64 \%(\mathrm{~N}=270)$ low back pain complaints, $25.6 \%(n=69)$ [95\% CI $(20.1,30.6)]$ had sought treatment services at least once in the previous 12 months. Slightly over half, $65.2 \%(n=45)$ of the respondents who sought medical care were females and $46.4 \%(n=32)$ of them were $>35$ years of age, while $23.2 \%$ $(\mathrm{n}=16)$ of them were $25-35$ years old. Twenty-six percent $(n=18)$ of the care seekers for low back pains were diploma and $43.5 \%(n=30)$ were first degree (Bachelor of Science) graduates. Regarding working hours, 58\% $(n=40)$ of interviewees reported they worked $>8 \mathrm{~h}$ per

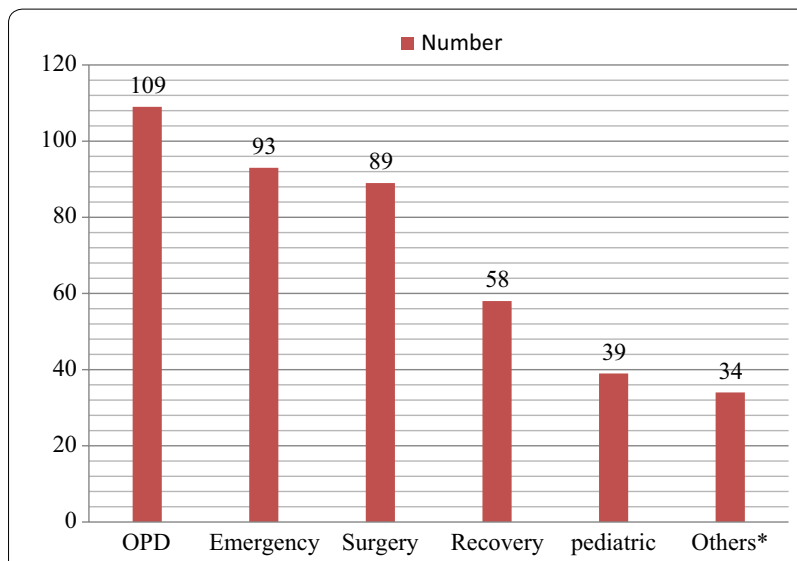

Fig. 1 Distribution of nurses by working department in Gondar town health facilities, Ethiopia, $2018(\mathrm{~N}=422)$

day, whereas $42 \%(n=29)$ of them indicated they had worked $\leq 8 \mathrm{~h}$ per day. About, $32 \%(\mathrm{n}=22)$ of the respondents exhibited they perceived their LBP complaints as a low disabling, while $68 \%(n=47)$ of them showed they perceived their symptoms as a high disabling pain. Seventy-eight percent of the nurses who sought treatment for LBP $(n=54)$ demonstrated their pain as a severe, whereas $21.7 \%(n=15)$ of them indicated not. Among the participants having had utilized treatment services for low back pains, $62.3 \%(n=43)$ clarified that they were not satisfied with their current jobs.

\section{Factors associated with healthcare utilization due to low back pains}

Sex, age, educational status, work experience, overtime work, working hours, duration of low back pain, job stress, job satisfaction, perceived severity, and perceived disability were the factors associated with healthcare utilization for low back pain in a bivariate analysis.

In the multivariable logistic regression analysis, sex, educational level, perceived severity of low back pain, and perceived disability were the factors markedly affected seeking care services for LBP. Females were 1.28 times more likely to seek healthcare services due to their low back pain than their male counterparts [AOR: 1.28; $95 \%$ CI $(1.03,3.43)]$. Participants who had held masters' degrees educational levels were 1.13 times more likely to seek treatment than who had diploma [AOR: 1.13; 95\% CI $(1.01,3.40)]$. The odds of health care utilization due to low back pain increased by a factor of 2.11 among participants who perceived their low back pain as a disabling than those who didn't perceive it as disabling pain [AOR: 2.11 ; 95\% CI $(1.66,3.30)]$. The likely hood of utilizing health care services was 2.06 times higher among respondents who perceived their low back pain as a 
severe than those who didn't [AOR: 2.06; 95\% CI (1.27, 3.51)] (Table 2).

\section{Discussion}

We first assessed the prevalence of low back pains, to investigate status and the factors affecting health service usage, out of the sufferers. The 12 months prevalence of low back pain was $64 \%(\mathrm{~N}=270)$ [95\% CI $(59.5,68.5)]$. Our finding demonstrates that, out of the victims, 25.6\%; [95\% CI (20.1-30.6)] had used healthcare services at least once in the previous 12 months. This finding was relatively equivalent to that of a study conducted in Switzerland (28\%) [20]. The possible reason could be due to similarities in the nature of healthcare facility working

Table 2 Factors affecting HCU for LBP among nurses, Gondar town, Ethiopia, 2018 ( $N=270$ )

\begin{tabular}{|c|c|c|c|c|c|}
\hline \multirow[t]{2}{*}{ Variables } & \multicolumn{2}{|c|}{ Healthcare utilization for LBP } & \multirow[t]{2}{*}{ COR $(95 \% \mathrm{Cl})$} & \multirow[t]{2}{*}{ AOR $(95 \% \mathrm{CI})$} & \multirow[t]{2}{*}{$p$-value } \\
\hline & Yes & No & & & \\
\hline \multicolumn{6}{|l|}{ Sex } \\
\hline Male & 24 & 100 & 1 & 1 & \\
\hline Female & 45 & 101 & $1.85(1.05,3.27)$ & $1.28(1.03,3.43)$ & $0.001^{*}$ \\
\hline \multicolumn{6}{|l|}{ Age } \\
\hline$<24$ years & 21 & 51 & 1 & 1 & \\
\hline $25-35$ years & 16 & 101 & $0.38(0.12-0.94)$ & $0.24(0.01-0.59)$ & $0.110^{+}$ \\
\hline$>35$ years & 32 & 49 & $1.60(1.05-.2 .51)$ & $1.31(0.03-2.03)$ & $0.071^{+}$ \\
\hline \multicolumn{6}{|l|}{ Educational level } \\
\hline Diploma & 18 & 87 & 1 & 1 & \\
\hline First degree (Bsc) & 30 & 80 & $1.81(0.99,3.40)$ & $1.12(0.73,2.17)$ & $0.061^{+}$ \\
\hline Masters degree & 21 & 34 & $2.98(0.76,3.96)$ & $1.13(1.01,3.40)$ & $0.003^{*}$ \\
\hline \multicolumn{6}{|l|}{ Job stress } \\
\hline Not stressed & 22 & 97 & 1 & 1 & \\
\hline Stressed & 47 & 104 & $1.99(1.11,3.54)$ & $1.08(1.21,2.17)$ & $0.078^{+}$ \\
\hline \multicolumn{6}{|l|}{ Work experience } \\
\hline$\leq 5$ years & 47 & 99 & 2.20 & $1.40(0.03,3.21)$ & $0.056^{+}$ \\
\hline$>5$ years & 22 & 102 & $(1.23,3.92)$ & 1 & \\
\hline \multicolumn{6}{|l|}{ Working hours per day } \\
\hline$\leq 8 \mathrm{~h}$ & 29 & 98 & 1 & 1 & \\
\hline$>8 \mathrm{~h}$ & 40 & 103 & $1.31(1.02,6.55)$ & $1.17(0.63,5.12)$ & $0.073^{+}$ \\
\hline \multicolumn{6}{|l|}{ Overtime } \\
\hline Yes & 56 & 161 & $1.07(0.53,2.14)$ & $1.01(0.07,4.30)$ & $0.081^{+}$ \\
\hline No & 13 & 40 & 1 & 1 & \\
\hline \multicolumn{6}{|l|}{ Job satisfaction } \\
\hline Satisfied & 26 & 91 & 1 & 1 & \\
\hline Not satisfied & 43 & 110 & $1.37(1.78,2.39)$ & $1.14(0.35,3.44)$ & $0.031^{+}$ \\
\hline \multicolumn{6}{|l|}{ Perceived disability } \\
\hline Low disability & 22 & 107 & 1 & 1 & \\
\hline High disability & 47 & 94 & $2.43(1.83,3.51)$ & $2.11(1.66,3.20)$ & $0.001^{*}$ \\
\hline \multicolumn{6}{|l|}{ Perceived severity } \\
\hline Severe pain & 54 & 120 & $2.43(1.28,4.60)$ & $2.06(1.27,3.51)]$ & $0.001^{*}$ \\
\hline Not severe pain & 15 & 81 & 1 & 1 & \\
\hline \multicolumn{6}{|l|}{ Duration of LBP } \\
\hline 0-7 days & 10 & 63 & 1 & 1 & \\
\hline $8-30$ days & 31 & 73 & $2.68(0.17,2.82)$ & $1.71(0.12,2.01)$ & \\
\hline$>30$ but not every day & 22 & 43 & $3.22(0.13,5.72)$ & $2.27(0.23,2.81)$ & \\
\hline Every day & 6 & 22 & $1.72(0.18,4.78)$ & $1.37(0.44,3.09)$ & $0.08^{*}$ \\
\hline
\end{tabular}

AOR, adjusted odds ratios; $\mathrm{Cl}$, confidence interval; $\mathrm{COR}$, Crude odds ratios; $\mathrm{HCU}$, Healthcare utilization; BSc, Bachelor of Science; LBP, low back pains

$1=$ represents reference categories; ${ }^{+}=$significant in a bivariate analysis; ${ }^{*}=$ significant in a multivariable analysis 
environments. But our result was higher than that of a study done in Nigeria (11.9\%) [29]. A possible explanation for this difference might be due to the variations in data collection methods and target populations. We found a lower prevalence of healthcare utilization for back pain compared to the reports from Malaysia (34.1\%) [10], Bangladesh (35\%) [30] and (36.2\%) [31], Norway (43\%) [32], Netherland (44\%) [33], India (45\%) [34], and the United States (84.0\%) [35]. These disparities might be because of differences in accessibility of health services, level of economic capacity to utilize medical services, variations in perceiving severity and disability of back pains, workplace illness and injury management and reporting procedures.

Our study demonstrated that sex was a significant factor for healthcare utilization due to LBP. According to this study, being female was more likely to increase the odds of seeking medical care because of low back pain than being male. This was in line with the findings of previous studies $[9,22,36]$. This could be due to the fact that females are usually cognizant of the benefits of using healthcare services. Another possible explanation might be that nursing is usually dominated by female professionals, which is true in the current study.

In this study, we found a considerable association between healthcare seeking due to low back pain and level of education. Previous studies reported similar findings [32, 37]. Education increases peoples' level of awareness and knowledge about the prevention and control of specific health problems.

The current study indicated that perceived severity of LBP remarkably affected seeking treatment services. Our result corroborated to other reports [20-22, 32, 33]. A possible suggestion is that severe back pain might negatively affect health status and the health professionals (nurses) become aware of the conditions after it has become serious. A previous study supports this explanation [22]. Perceived disability is the other factor that significantly predicted decision to seek healthcare utilization due to low back pain. This finding corresponds to the other studies [20, 22, 32, 33]. This could be explained by the awareness and knowledge of nurses about the ultimate consequences of their ailments that predisposes them to use healthcare, probably when their condition begins to manifest impairments in their daily activities.

\section{Conclusions}

This study reveals that healthcare service utilization for low back pain is not common practices among nurses. Strategies that focus on nurses' gender and educational level differences should be in place to promote care usage for LBP. Procedures that can address pains related to back pains is also an imperative approach to encourage nurses' care seeking for low back pain.

\section{Limitations}

The self-report data collection method employed in the current study might be one of the suspected limitations, leading to underestimation (due to recall bias). It might also be problematic to judge a temporal-relationship between healthcare usage due to LBP and the factors that affect it only by using a cross-sectional design. Moreover, it might be uncertain to generalize the findings of the study, as the study was dealt with only a specific segment of workforces. Therefore, future investigations with a large sample from various sectors and strong study designs, such as longitudinal, are greatly suggested.

\section{Abbreviations}

AOR: adjusted odds ratios; BMI: body mass index; BSc: Bachelor of Science; $\mathrm{Cl}$ : confidence interval; COR: Crudes odds ratios; HCU: Health care utilization; KM: kilometer; LBP: low back pain; MPH: Masters of public health; OR: odds ratios; SD: standard deviations; SPSS: Statistical Package for Social Sciences.

\section{Authors' contributions}

THM: Initiated the research concept, analyzed the data, presented the results and discussions, wrote up of the draft manuscript, reviewed and finalized the manuscript document, and the corresponding author. DGY: Wrote up of the research proposal, involved in data analysis, interpreted results, involved in manuscript writing and reviewing. Both authors read and approved the final manuscript.

\section{Acknowledgements \\ The authors would like to extend our warmest thanks to the Department of Environmental and Occupational Health and Safety, Institute of Public Health, College of Medicine and Health Sciences, University of Gondar for provid- ing ethical clearance. All the participants and data collectors were greatly appreciated.}

\section{Competing interests}

The authors declare that they have no competing interests.

\section{Availability of data and materials}

The datasets generated and analyzed during this study were included in the main document of this manuscript and available from the corresponding author on reasonable request.

\section{Consent for publication}

Not applicable.

\section{Ethics approval and consent to participate}

The ethical clearance was obtained from the Institutional Ethical Review Board (IERB) of the University of Gondar, Institute of Public Health (Reference No \#: EOHS/563/2010). We submitted this letter to the health facilities selected by being eligible. Verbal consent from each participant was then obtained. Participation was voluntary and withdrawal from the study at any point during data collection was highly respected. Only aggregate data were used for the interpretation of the results to ensure and maintain the confidentiality of the data.

\section{Funding}

Department of Environmental and Occupational Health and Safety, Institute of Public Health, the University of Gondar, covered the financial cost of this study but did not involve in any of the activities. 


\section{Publisher's Note}

Springer Nature remains neutral with regard to jurisdictional claims in published maps and institutional affiliations.

Received: 8 January 2019 Accepted: 26 March 2019

Published online: 29 March 2019

\section{References}

1. Hoy D, March L, Brooks P, Blyth F, Woolf A, Bain C, Williams G, Smith E, Vos $T$, Barendregt J. The global burden of low back pain: estimates from the Global Burden of Disease 2010 study. Ann Rheum Dis. 2014;73(6):968-74.

2. Alem D, Ephrem M, Seblewengel L. Prevalence of low back pain and associated risk factors among Adama Hospital Medical College Staff, Ethiopia. Eur J Prev Med. 2015;3(6):188-92.

3. Hagen KB, Dagfinrud H, Moe RH, Østerås N, Kjeken I, Grotle M, Smedslund G. Exercise therapy for bone and muscle health: an overview of systematic reviews. BMC Med. 2012;10(167):1-11.

4. Ehrlich George E. Low back pain/Ehrlich George E. Bull World Health Organ. 2003;81:671-6.

5. Tomita S, Arphorn S, Muto T, Koetkhlai K, Naing SS, Chaikittiporn C. Prevalence and risk factors of low back pain among Thai and Myanmar migrant seafood processing factory workers in Samut Sakorn Province, Thailand. Ind Health. 2010;48(3):283-91

6. Karahan A, Kav S, Abbasoglu A, Dogan N. Low back pain: prevalence and associated risk factors among hospital staff. J Adv Nurs. 2009:65(3):516-24.

7. Ma Abbas. Zaid laz, Fialala, Alhamdanna: Prevalence and risk factors of low back pain among nurses in four tertiary care hospitals at King Fahad Medical City, Riyadh, KSA. Med J Cairo Univ. 2010;78(2):219-23.

8. Shieh S-H, Sung F-C, Su C-H, Tsai Y. Hsieh VC-R: increased low back pain risk in nurses with high workload for patient care: a questionnaire survey. Taiwan J Obstet Gynecol. 2016;55(4):525-9.

9. Ghilan K, Al-Taiar A, Yousfi N, Zubaidi R, Awadh I, Al-Obeyed Z. Low back pain among female nurses in Yemen. Int J Occup Med Environ Health. 2013;26(4):605-14.

10. Wong T, Teo N, Kyaw M. Prevalence and risk factors associated with low back among health care providers in a District Hospital. Malaysian Orthop J. 2010;4(2):23-8.

11. Bana S, Yakoob J, Jivany N, Faisal A, Jawed H, Awan S. Understanding health seeking behavior of health care professionals in tertiary care hospitals in Pakistan. J Ayub Med Coll Abbottabad. 2016;28(3):545-9.

12. Hayashi Y. Classification, diagnosis, and treatment of low back pain. Japan Med Assoc J. 2004:47(5):227-33.

13. Sailaja AK. Treatment for low back pain attributed to underlying presumptive etiology. Am J Drug Deliv Therap. 2015;2(1):001-8.

14. Jensen RK, Leboeuf-Yde C, Wedderkopp N, Sorensen JS, Manniche C. Rest versus exercise as treatment for patients with low back pain and Modic changes. A randomized controlled clinical trial. BMC Med. 2012;10(22):1-13.

15. Tilbrook HE, Cox H, Hewitt CE, Kang'ombe AR, Chuang L-H, Jayakody S, Aplin JD, Semlyen A, Trewhela A, Watt I. Yoga for chronic low back pain: a randomized trial. Ann Intern Med. 2011:155(9):569-78.

16. Hsieh LL-C, Kuo C-H, Lee LH, Yen AM-F, Chien K-L, Chen TH-H. Treatment of low back pain by acupressure and physical therapy: randomised controlled trial. BMJ. 2006;332(7543):696-700.

17. Saper RB, Boah AR, Keosaian J, Cerrada C, Weinberg J, Sherman KJ. Comparing once-versus twice-weekly yoga classes for chronic low back pain in predominantly low income minorities: a randomized dosing trial. Evid Based Complement Altern Med. 2013;2013(2013):1-14.

18. Picavet HSJ, Struijs JN, Westert GP. Utilization of health resources due to low back pain: survey and registered data compared. Spine. 2008:33(4):436-44.

19. Plénet A, Gourmelen J, Chastang J-F, Ozguler A, Lanoë J-L, Leclerc A. Seeking care for lower back pain in the French population aged from 30 to 69: the results of the 2002-2003 Decennale Sante survey. Ann Phys Rehabil Med. 2010:53(4):224-38.

20. Mannion AF, Wieser S, Elfering A. Association between beliefs and careseeking behavior for low back pain. Spine. 2013;38(12):1016-25.

21. Tiira A, Paananen M, Taimela S, Zitting P, Järvelin MR, Karppinen J. Determinants of adolescent health care use for low back pain. Eur J Pain. 2012:16(10):1467-76.

22. Ferreira ML, Machado G, Latimer J, Maher C, Ferreira PH, Smeets RJ. Factors defining care-seeking in low back pain-a meta-analysis of population based surveys. Eur J Pain. 2010;14(7):747.

23. Görge M, Ziehm J, Farin E. Health-care utilization of patients with chronic back pain before and after rehabilitation. BMC Health Serv Res. 2017:17(1):812

24. Molano S, Burdorf A, Elders L. Factors associated with medical care-seeking due to low-back pain in scaffolders. Am J Ind Med. 2001;40(3):275-81.

25. Kuorinka I, Jonsson B, Kilbom A, Vinterberg H, Biering-Sørensen F, Andersson G, Jørgensen K. Standardised Nordic questionnaires for the analysis of musculoskeletal symptoms. Appl Ergonom. 1987;18(3):233-7.

26. Von Korff M, Ormel J, Keefe FJ, Dworkin SF. Grading the severity of chronic pain. Pain. 1992:50(2):133-49.

27. Macdonald S, Maclntyre P. The generic job satisfaction scale: scale development and its correlate. Employee Assist Q. 1997;13(2):1-16.

28. The Marlin Company NH, CT and the American Institute of Stress, Yonkers, NY: The Workplace Stress Scale. https://teorionline.files.wordpress. com/2011/04/unit-3-the-workplace-stress-scale.pdf. Accessed 14 Aug 2018.

29. Akinpelu A, Oyewole O, Odole A, Olukoya R. Prevalence of musculoskeletal pain and health seeking behaviour among occupational drivers in Ibadan, Nigeria. Afr J Biomed Res. 2011;14(2):89-94.

30. Md KBS, Khan S, Md SH, Sizear MI. Alam Au, Md MH: Socioeconomic Status \& Health Seeking Behavior of Rural People: a Cross Sectional Study in Fatikchhari, Chittagong. MOJ Public Health. 2016;4(4):1-5.

31. Sanjoy SS, Ahsan GU, Nabi H, Joy ZF, Hossain A. Occupational factors and low back pain: a cross-sectional study of Bangladeshi female nurses. BMC Res Notes. 2017:10(173):1-6.

32. Woodhouse A, Pape K, Romundstad PR, Vasseljen O. Health care contact following a new incident neck or low back pain episode in the general population; the Hunt study. BMC Health Serv Res. 2016;16(81):1-10.

33. Molano S, Burdorf A, Elders L. Factors associated with medical care seeking due to low back pain in scaffolders. Am J Ind Med. 2001;40(3):275-81.

34. Mendhe HG, Hanumanth N, Harika G. A study on musculoskeletal disorders distribution and health-seeking behavior among geriatric people in the field practice area of rural health and training center of a tertiary care hospital. Int J Med Sci Public Health. 2016;5(11):2226-9.

35. Freburger JK, Holmes GM, Agans RP, Jackman AM, Darter JD, Wallace AS, Castel LD, Kalsbeek WD, Carey TS. The rising prevalence of chronic low back pain. Arch Intern Med. 2009;169(3):251-8.

36. Chevan J, Riddle DL. Factors associated with care seeking from physicians, physical therapists, or chiropractors by persons with spinal pain: a population-based study. J Orthop Sports Phys Ther. 2011;41(7):467-76.

37. MacNaughton NS. Health disparities and health-seeking behavior among Latino men: a review of the literature. J Transcult Nurs. 2008;19(1):83-91. 